\title{
An abdominal ectopic pregnancy following a frozen-thawed ART cycle: a case report and review of the literature
}

\author{
Atsushi Yanaihara ${ }^{1 *}$, Shirei Ohgi ${ }^{1}$, Kenichirou Motomura ${ }^{1}$, Yuko Hagiwara ${ }^{2}$, Tae Mogami ${ }^{2}$, Keisuke Saito ${ }^{2}$ \\ and Takumi Yanaihara'
}

\begin{abstract}
Background: Ectopic pregnancy (EP) occurs in 1\% of pregnancies and is reported to be more common in in vitro fertilization/intracytoplasmic sperm injection (IVF/ICSI) pregnancies. An abdominal ectopic pregnancy (AEP) is a rare form of EP, and there are few reports of an AEP after IVF/ICSI. In this case report, a rare case of AEP after frozen-thawed cycle of ICSI is presented.

Case presentation: After a frozen-thawed cycle of ICSI, the beta-human chorionic gonadotropin (HCG) level at 4 weeks 0 days of gestation was $3.4 \mathrm{IU} / \mathrm{L}$. Subsequent dysfunctional uterine bleeding was mistaken for menstruation; however, an AEP of 9 weeks with a fetal heart beat was observed by ultrasound. After the AEP was observed by ultrasound, it was extracted laparoscopically.

Conclusion: A rare case of an AEP, which developed after frozen-thawed cycle of ICSI, presented with a very low serum HCG level. Even if the HCG titer is low, follow-up HCG levels and frequent medical examinations are necessary.
\end{abstract}

Keywords: Abdominal ectopic pregnancy, HCG, Laparoscope, IVF, Case report

\section{Background}

Ectopic pregnancies (EP) occur in approximately $1 \%$ of all pregnancies, although traditionally the incidence is thought to be significantly higher in pregnancies resulting from in in vitro fertilization/intracytoplasmic sperm injection (IVF/ICSI) treatment $[1,2]$. This has particularly been reported to be the case for women with tubal rather than non-tubal infertility [3, 4]. Multivariable logistic regression analyses have also accordingly demonstrated that the major risk factor for EP is the presence of tubal infertility, followed by an increased number of embryos transferred. On the other hand, extended embryo culture, such as blastocyst transfer, has shown to significantly reduce the risk of EP, while frozen-thawed embryo transfer (T-ET) has shown no effect on the risk of EP following IVF/ICSI [5-7].

\footnotetext{
* Correspondence: at123y@yahoo.co.jp

${ }^{1}$ Yanaihara Women's Clinic, 1-26-29 Ofuna, Kamakura, Kanagawa Zip247-0056, Japan

Full list of author information is available at the end of the article
}

As over $90 \%$ of EP are tubal pregnancies, abdominal ectopic pregnancies (AEP) constitute a rare form of $\mathrm{EP}$, with increasing morbidity and difficulty in diagnosis $[5,8]$. In this article a case of AEP is presented, which occurred following a single T-ET cycle of ICSI in a woman with non-tubal infertility. The betahuman chorionic gonadotropin (HCG) level was very low at 4 weeks 0 days of gestation, highlighting the difficulty such cases can pose for diagnosis and management.

\section{Case presentation}

A 37-year-old primipara who had had three previous intrauterine inseminations (IUI) at another clinic was referred to our clinic for a second opinion. She had been undergoing infertility treatment for five years. Clinical information forwarded from the previous clinic included: semen analysis, within normal limits; hysterosalpingography, patent Fallopian tubes; serum hormone levels, within normal limits (Day 3, follicle-stimulating hormone $11.3 \mathrm{IU} / \mathrm{L}$, luteinizing hormone $2.4 \mathrm{IU} / \mathrm{L}$, 
prolactin $11.3 \mathrm{ng} / \mathrm{ml}$; Day 20, estradiol $113 \mathrm{pg} / \mathrm{ml}$, progesterone $15.6 \mathrm{ng} / \mathrm{ml}$ ). The clinical findings at out clinic were: transvaginal ultrasound, uterine myoma $(2.7 \mathrm{~cm})$ in the muscular layer; endometrium, no irregularity; postcoital test, negative; and antisperm antibody, negative.

The patient underwent one IUI in our clinic; subsequently, she and her husband agreed to undergo IVF for infertility of unknown origin. The IVF process entailed ovarian stimulation with clomiphene plus human menopausal gonadotropin injections for two cycles [9]. Four ova were harvested, and three were fertilized via ICSI. Although semen analysis was previously reported as normal, ICSI was performed during the IVF/ICSI cycle due to a low motility $(<10 \%)$ found during that cycle. In the next cycle, intrauterine T-ET of one blastocyst (5BA grade; Gardner criteria) was done with a hormone replacement cycle under ultrasound guidance with a soft-tipped catheter by a boardcertified member of the Japan Society for Reproductive Medicine. The endometrial thickness was $10.5 \mathrm{~mm}$, and the embryo was expelled into the uterine cavity approximately $1 \mathrm{~cm}$ from the uterine fundus with good visualization. A subsequent pregnancy test was negative, and the serum $\beta$-HCG was $3.4 \mathrm{IU} / \mathrm{L}$ at 4 weeks 0 days of gestation from T-ET (post-transfer 9 days). A re-examination was planned for day 3 of the menstrual cycle or one week if menses did not occur. Four days later, the patient called and informed us that menstruation had begun, but she was unable to come to the clinic because of her business schedule; therefore, we advised her to present at the clinic 12 days after menstruation began. At that time (post-transfer 24 days), a transvaginal ultrasound imaged a folliclelike circle with low echogenicity near the Pouch of Douglas; thus, we advised her that, based on her menstrual cycle, it was a good date for sexual intercourse. She was not able to present for her next examination for ovulation because of other commitments. Twentyseven days after her menses began (post-transfer 40 days), she informed us that her urinary pregnancy test was positive. She presented at our clinic the following day, and a second urinary pregnancy test was also positive (post-transfer 46 day, 9 weeks 3 days of gestation).

Transvaginal ultrasound was performed and a gestational sac (GS) could not be located in the uterus, but there was a GS containing a fetus consistent with 8 weeks 6 days of gestation (crown rump length: $18.8 \mathrm{~mm}$ ) near the pouch of Douglas. (Fig. 1) An EP was diagnosed, and the patient was transported to another hospital because our clinic does not have an operating room suitable for laparoscopy. The laparoscopic diagnosis was an unruptured AEP of the pouch of Douglas.

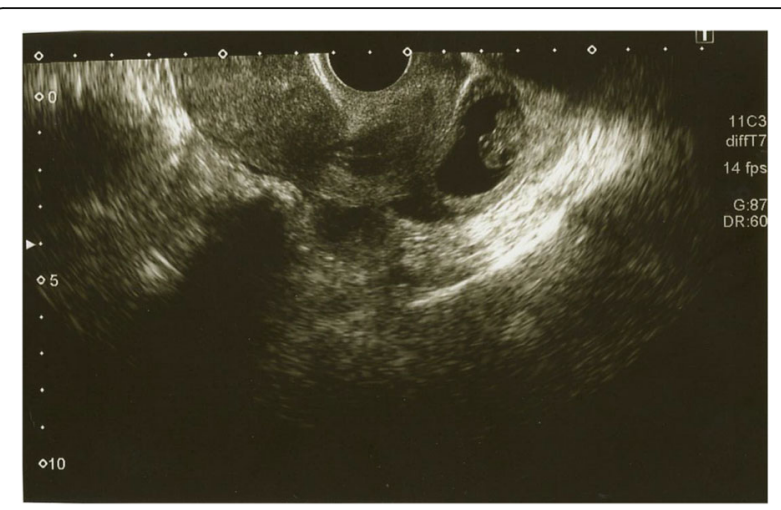

Fig. 1 Ultrasound of gestational sac near Douglas cavum

(Fig. 2). The gestational tissue was removed by forceps, and electrocauterization was used for hemostasis under laparoscopic surgery. The serum $\beta$-HCG was less than $0.5 \mathrm{IU} / \mathrm{L} 33$ days after surgery.

\section{Discussion and Conclusions}

Recently, the diagnosis of EP has been possible before rupture because of a new technique for improving ultrasound diagnosis and improving early sensitive serum HCG measurements [10]. It is difficult to discover an EP during a spontaneous pregnancy, but, for a patient who presents regularly at a hospital during early gestation, early diagnosis is facilitated. It is sometimes still difficult to discriminate between an EP and a miscarriage during early gestation. However, the literature contains a number of reports addressing the association between EP and a frozen-thawed IVF/ICSI cycle. Many reports have suggested that frozen embryo transfer has no effect on the risk of EP [5, 11-13]. In addition, frozen-thawed day 5 blastocyst transfer is associated with a lower risk of EP than either day 3 transfer or fresh transfer [14]. A peritoneal pregnancy is rarer, and the incidence of EP has been reported to be $0.9 \%$. It has also been reported that the mortality

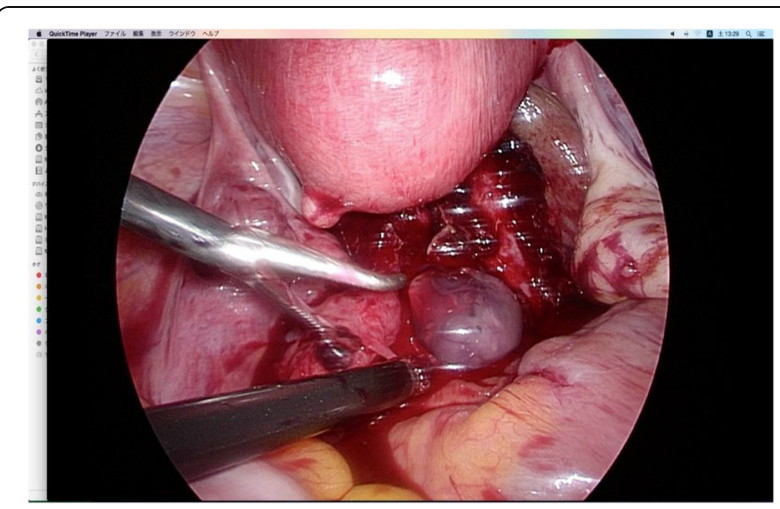

Fig. 2 Laparoscopic view of gestational sac near Douglas cavum 
rate is 7.7 times higher than other types of EP [15]. It is thought that this is because intra-abdominal hemorrhage is more common in an EP than a tubal pregnancy, and the symptoms have an abrupt onset and progression. It was fortunate that an intra-abdominal pregnancy was avoided in the present case, but the risk is ever-present.

This case illustrates the following points:

1. This case was very likely to be misdiagnosed as a miscarriage because the serum $\beta$-HCG at 4 weeks 0 days from T-ET was quite low (3.4 IU/L). However, the literature contains a report of a ruptured EP with an HCG level of $<10$ IU/L [16]. Thus, we must keep the possibility of an EP in mind at all times, even if the HCG titer is very low.

2. The bleeding 4 days after the diagnosis of pregnancy was misdiagnosed as menstruation via a telephone conversation; however, it was actually dysfunctional uterine bleeding. This situation can often occur during a normal pregnancy.

3. A gestational sac or follicle was not detected when the patient presented at our clinic 12 days after the onset of menses. Based on the day of transfer, a yolk sac should have been observed within the echogenic area, and it should have been determined that the echogenic area was not a follicle.

It was fortunate in this case that a rupture did not occur. The pouch of Douglas might be an area where minimal friction between the EP.

There are some previous reports of EP, and many have undergone surgery or diagnostic examination laparosco pically.

\begin{tabular}{|c|c|c|c|c|c|c|c|}
\hline \multirow[t]{2}{*}{ Author (year) } & \multirow[t]{2}{*}{ Age } & \multirow{2}{*}{$\begin{array}{l}\text { Infertility } \\
\text { diagnosis }\end{array}$} & Fresh & NET & SET & Operation & Outcome \\
\hline & & & \multicolumn{3}{|c|}{ /Frozen ET } & \multicolumn{2}{|l|}{ /diagnosis } \\
\hline Oehniger (1988) [17] & 35 & endometriosis & Fresh & 4 & 2 & Laparotomy & Removal of pregnancy tissue \\
\hline Bassil (1991) [18] & 33 & male factor & Fresh & 4 & unknown & Laparotomy & Delivery of viable twins at 34 weeks \\
\hline Ferland (1991) [19] & 32 & tubal factor & Fresh & 3 & 2 & Laparotomy & Removal of pregnancy tissue \\
\hline Ragni (1991) [20] & 32 & pelvic disease & Fresh & 3 & 2 & Laparotomy & Removal of pregnancy tissue \\
\hline Balmaceda (1993) [21] & 33 & tubal factor & Fresh & 4 & 4 & Laparoscopy & Removal of pregnancy tissue \\
\hline Fisch (1995) [22] & 32 & tubal factor & Fresh & 3 & unknown & Laparotomy & Removal of pregnancy tissue \\
\hline DelRosario (1996) [23] & 33 & tubal factor & Frozen & 4 & unknown & Laparoscopy & Removal of pregnancy tissue \\
\hline Fisch (1996) [24] & 38 & tubal factor & Fresh & 4 & 3 & Laparotomy & Removal of pregnancy tissue \\
\hline Moonen-Delarue (1996) [25] & 23 & pelvic disease & Fresh & unknown & unknown & Laparotomy & Removal of pregnancy tissue \\
\hline Pisarska (1998) [26] & 35 & unexplained & Fresh & 6 & unknown & Laparoscopy & Removal of pregnancy tissue \\
\hline Deshpande (1999) [27] & 33 & endometriosis & Fresh & 2 & 3 & Laparotomy & Removal of pregnancy tissue \\
\hline Scheiber (1999) [28] & 37 & tubal factor & Frozen & 2 & 3 & Chemical & $\mathrm{KCL}$ \\
\hline Dmowski (2002) [29] & 34 & tubal factor & Fresh & 3 & 3 & Laparotomy & Removal of pregnancy tissue \\
\hline Jain (2002) [30] & 29 & unexplained & unknown & 2 & unknown & Laparotomy & Removal of pregnancy tissue \\
\hline Cormio (2003) [31] & 30 & tubal factor & Fresh & 4 & 3 & Laparotomy & Removal of pregnancy tissue \\
\hline Reid (2003) [32] & 28 & tubal factor & unknown & 3 & unkown & Laparotomy & Removal of pregnancy tissue \\
\hline Kitade (2005) [33] & 37 & unexplained & Fresh & 3 & 3 & Laparoscopy & Removal of pregnancy tissue \\
\hline Ali (2006) [15] & 35 & tubal factor & Fresh & 1 & unkown & Laparoscopy & Removal of pregnancy tissue \\
\hline Apantaku (2006) [34] & 33 & tubal factor & Fresh & 2 & unkown & Laparoscopy & Removal of pregnancy tissue \\
\hline Knopman (2007) [35] & 37 & unexplained & Fresh & 2 & 5 & Laparoscopy & Removal of pregnancy tissue \\
\hline Shih (2007) [36] & 33 & male factor & Fresh & unkown & unkown & Laparoscopy & Removal of pregnancy tissue \\
\hline Shojai (2007) [37] & 35 & structural & unknown & 3 & unkown & Laparotomy & Delivery of viable twins at 32 weeks \\
\hline Iwama (2008) [38] & 31 & tubal factor & Fresh & 3 & 3 & Laparotomy & Removal of pregnancy tissue \\
\hline Hyvarinen (2009) [39] & unknown & unknown & unknown & unknown & unknown & Laparotomy & 30 weeks delivery \\
\hline Zacche (2011) [40] & 36 & tubal factor & Fresh & 2 & unknown & Laparotomy & Delivery of viable twins at 30 weeks \\
\hline Angelova (2015) [41] & 33 & male factor & Fresh & 2 & 3 & Laparoscopy & Removal of pregnancy tissue \\
\hline Yoder (2016) [8] & 30 & male factor & Fresh & 1 & 5 & Laparoscopy & Removal of pregnancy tissue \\
\hline
\end{tabular}


NET Number of embryo(s) transferred, SET Stage of embryo transferred

Among the EP cases, some have been reported to continue to term [42, 43], and in EP after IVF/ICSI, there have been cases that were delivered [18].

Yoder et al. have recently reported a systematic review of 29 cases (including their case) of AEP after IVF/ICSI. According to their review, several trends of AEP were identified. The majority of cases $(61 \%)$ had a history of anatomic/structural infertility with a history of tubal factor infertility (46\%). This was consistent with tubal factor infertility being a known risk factor for ectopic pregnancy following IVF/ICSI. In addition, a history of tubal EP was particularly common, being reported in $37 \%$ of the abdominal ectopic cases. A history of prior tubal surgery was also particularly common (50\%) among abdominal ectopic cases in their systematic review. Fresh embryo transfer was far more common in abdominal ectopic cases than frozen embryo transfer (11\% of cases) [8].

The risk of EP after IVF/ICSI is increased by the number of embryos [6, 7]. As a mechanism for AEP by IVF/ ICSI, aspects of the transfer that may increase the risk of EP include a large volume of transfer media, induction of abnormal uterine contractions, and the location of the embryo transfer in relation to the uterine fundus [10]. Bu et al. reported that the rate of EP was positively associated with ovarian stimulation for fresh IVF/ICSI cycles [6]. The endometrial combined thickness was also linked to an increased risk of EP [44]. Thus, it may be that EP may occur when some factors are present at the same time.

The present case was a rare occurrence, and AEP can occur even in cases where the index of suspicion would be theoretically low. The cause of AEP is unknown at present, and it is difficult to prevent. Technical improvement of IVF/ICSI may lower its incidence if IVF/ICSI is hypothesized to be one cause of EP. Further study is necessary to avoid this rare IVF/ICSI complication.

\section{Abbreviations}

AEP: Abdominal ectopic pregnancy; EP: Ectopic pregnancy; GS: Gestational sac; HCG: Human chorionic gonadotropin; ICSI: Intracytoplasmic sperm injection; IUI: Intrauterine inseminations; IVF: Conventional in vitro fertilization; T-ET: Thawed embryo transfer

\section{Acknowledgements}

The authors would like to thank Dr.Luba Wolchuk who provided medical writing services on behalf of Forte Inc.

\section{Funding}

Not applicable.

\section{Availability of data and materials}

All data of this case report are available in this manuscript.

\section{Authors' contributions}

AY and SO drafted the manuscript. YH, TM, and KS performed laparoscopic surgery. TY and KM helped draft the manuscript. All authors read and approved the final manuscript.

\section{Competing interests}

The authors report no conflict of interest concerning the materials or methods used in this case report or the findings specified in this paper. The authors have no competing financial interests related to this case report.

\section{Consent for publication}

Written informed consent was obtained from the patient for publication of this case report and any accompanying images.

\section{Ethics approval and consent to participate}

This case report was conducted with the approval of the Ethics Committee of Yanaihara Women's Clinic and with patient consent (ERBY/3, 2016).

\section{Publisher's Note}

Springer Nature remains neutral with regard to jurisdictional claims in published maps and institutional affiliations.

\section{Author details}

${ }^{1}$ Yanaihara Women's Clinic, 1-26-29 Ofuna, Kamakura, Kanagawa Zip247-0056, Japan. ${ }^{2}$ Department of Obstetrics \& Gynecology, Women's Health, Yokohama City University Hospital, 3-9 Fukuura Kanazawa-ku, Yokohama Zip 236-0004, Japan.

Received: 5 May 2016 Accepted: 24 March 2017

Published online: 07 April 2017

\section{References}

1. Strandell A, Thorburn J, Hamberger L. Risk factors for ectopic pregnancy in assisted reproduction. Fertil Steril. 1999;71(2):282-6.

2. Kamath MS, Aleyamma TK, Muthukumar K, Kumar RM, George K. A rare case report: ovarian heterotopic pregnancy after in vitro fertilization. Fertil Steril. 2010;94(5):1910. e1919-1911.

3. Li C, Zhao WH, Zhu Q, Cao SJ, Ping H, Xi X, Qin GJ, Yan MX, Zhang D, Qiu J, et al. Risk factors for ectopic pregnancy: a multi-center case-control study. BMC Pregnancy childbirth. 2015:15:187.

4. Pyrgiotis E, Sultan KM, Neal GS, Liu HC, Grifo JA, Rosenwaks Z. Ectopic pregnancies after in vitro fertilization and embryo transfer. J Assist Reprod Genet. 1994;11(2):79-84.

5. Santos-Ribeiro S, Tournaye H, Polyzos NP. Trends in ectopic pregnancy rates following assisted reproductive technologies in the UK: a 12-year nationwide analysis including 160000 pregnancies. Human Reprod (Oxford, England). 2016:31(2):393-402.

6. Bu Z, Xiong Y, Wang K, Sun Y. Risk factors for ectopic pregnancy in assisted reproductive technology: a 6-year, single-center study. Fertil Steril. 2016; 106(1):90-4

7. Yanaihara A, Yorimitsu T, Motoyama H, Ohara M, Kawamura T. Clinical outcome of frozen blastocyst transfer; single vs. double transfer. J Assist Reprod Genet. 2008;25(11-12):531-4.

8. Yoder N, Tal R, Martin JR. Abdominal ectopic pregnancy after in vitro fertilization and single embryo transfer: a case report and systematic review. Reprod Biol Endocrinol. 2016;14(1):69.

9. Yanaihara AYT, Motoyama H, Iwasaki S, Kawamura T. Mild stimulation with clomiphene citrate in combination with recombinant follicle-stimulating hormone and gonadotropin-releasing hormone antagonist and its influence on serum estradiol level and pregnancy rate. Reprod Med Biol. 2008;7:85-9.

10. Refaat B, Dalton E, Ledger WL. Ectopic pregnancy secondary to in vitro fertilisation-embryo transfer: pathogenic mechanisms and management strategies. Reprod Biol Endocrinol. 2015;13:30.

11. Londra L, Moreau C, Strobino D, Garcia J, Zacur H, Zhao Y. Ectopic pregnancy after in vitro fertilization: differences between fresh and frozen-thawed cycles. Fertil Steril. 2015;104(1):110-8.

12. Huang B, Hu D, Qian K, Ai J, Li Y, Jin L, Zhu G, Zhang H. Is frozen embryo transfer cycle associated with a significantly lower incidence of ectopic pregnancy? An analysis of more than 30,000 cycles. Fertil Steril. 2014; 102(5):1345-9.

13. Decleer W, Osmanagaoglu K, Meganck G, Devroey P. Slightly lower incidence of ectopic pregnancies in frozen embryo transfer cycles versus fresh in vitro fertilization-embryo transfer cycles: a retrospective cohort study. Fertil Steril. 2014;101(1):162-5. 
14. Fang C, Huang R, Wei LN, Jia L. Frozen-thawed day 5 blastocyst transfer is associated with a lower risk of ectopic pregnancy than day 3 transfer and fresh transfer. Fertil Steril. 2015;103(3):655-61. e653.

15. Ali CR, Fitzgerald C. Omental and peritoneal secondary trophoblastic implantation - an unusual complication after IVF. Reprod Biomed Online. 2006;12(6):776-8

16. Fu J, Henne MB, Blumstein S, Lathi RB. Rupture of ectopic pregnancy with minimally detectable beta-human chorionic gonadotropin levels: a report of 2 cases. J Reprod Med. 2007;52(6):541-2.

17. Oehninger S, Kreiner D, Bass MJ, Rosenwaks Z. Abdominal pregnancy after in vitro fertilization and embryo transfer. Obstet Gynecol. 1988;72(3 Pt 2): 499-502.

18. Bassil S, Pouly JL, Canis M, Janny L, Vye P, Chapron C, Bruhat MA. Advanced heterotopic pregnancy after in-vitro fertilization and embryo transfer, with survival of both the babies and the mother. Human Reprod (Oxford, England). 1991;6(7):1008-10.

19. Ferland RJ, Chadwick DA, O'Brien JA, Granai 3rd CO. An ectopic pregnancy in the upper retroperitoneum following in vitro fertilization and embryo transfer. Obstet Gynecol. 1991;78(3 Pt 2):544-6.

20. Ragni G, Lombroso Finzi GC, Olivares MD, Crosignani PG. Twin in vitro fertilization (IVF) pregnancies: spontaneous intrauterine abortion after selective secondtrimester termination of ectopic intraabdominal pregnancy. J In Vitro Fert Embryo Transf. 1991;8(4):236-7.

21. Balmaceda JP, Bernardini L, Asch RH, Stone SC. Early primary abdominal pregnancy after in vitro fertilization and embryo transfer. J Assist Reprod Genet. 1993;10(4):317-20.

22. Fisch B, Powsner E, Heller L, Goldman GA, Tadir Y, Wolloch J, Ovadia J. Heterotopic abdominal pregnancy following in-vitro fertilization/embryo transfer presenting as massive lower gastrointestinal bleeding. Human Reprod (Oxford, England). 1995;10(3):681-2.

23. delRosario R, el-Roeiy A. Abdominal pregnancy on the bladder wall following embryo transfer with cryopreserved-thawed embryos: a case report. Fertil Steril. 1996;66(5):839-41.

24. Fisch B, Peled Y, Kaplan B, Zehavi S, Neri A. Abdominal pregnancy following in vitro fertilization in a patient with previous bilateral salpingectomy. Obstet Gynecol. 1996;88(4 Pt 2):642-3.

25. Moonen-Delarue MW, Haest JW. Ectopic pregnancy three times in line of which two advanced abdominal pregnancies. Eur J Obstet Gynecol Reprod Biol. 1996;66(1):87-8

26. Pisarska MD, Casson PR, Moise Jr KJ, DiMaio DJ, Buster JE, Carson SA. Heterotopic abdominal pregnancy treated at laparoscopy. Fertil Steril. 1998;70(1):159-60.

27. Dhorepatil B, Rapol A. A rare case of unruptured viable secondary ovarian pregnancy after IVF/ICSI treated by conservative laparoscopic surgery. J Human Reprod Sci. 2012;5(1):61-3.

28. Scheiber MD, Cedars MI. Successful non-surgical management of a heterotopic abdominal pregnancy following embryo transfer with cryopreserved-thawed embryos. Human Reprod (Oxford, England). 1999;14(5):1375-7.

29. Dmowski WP, Rana N, Ding J, Wu WT. Retroperitoneal subpancreatic ectopic pregnancy following in vitro fertilization in a patient with previous bilateral salpingectomy: how did it get there? J Assist Reprod Genet. 2002;19(2):90-3.

30. Jain S, Justus K, Bober S. Selective transvaginal embryo reduction in heterotopic pregnancy located intra-abdominally. J Obstet Gynaecol. 2002;22(3):330.

31. Cormio G, Santamato S, Putignano G, Bettocchi S, Pascazio F. Concomitant abdominal and intrauterine pregnancy after in vitro fertilization in a woman with bilateral salpingectomy. A case report. J Reprod Med. 2003;48(9):747-9.

32. Reid F, Steel M. An exceptionally rare ectopic pregnancy. BJOG. 2003; 110(2):222-3.

33. Kitade M, Takeuchi H, Kikuchi I, Shimanuki H, Kumakiri J, Kinoshita K. A case of simultaneous tubal-splenic pregnancy after assisted reproductive technology. Fertil Steril. 2005;83(4):1042.

34. Apantaku O, Rana P, Inglis T. Broad ligament ectopic pregnancy following in-vitro fertilisation in a patient with previous bilateral salpingectomy. J Obstet Gynaecol. 2006;26(5):474.

35. Knopman JM, Talebian S, Keegan DA, Grifo JA. Heterotopic abdominal pregnancy following two-blastocyst embryo transfer. Fertil Steril. 2007;88(5): 1437. e1413-1435.

36. Shih CC, Lee RK, Hwu YM. Cul-de-sac pregnancy following in vitro fertilization and embryo transfer. Taiwan J Obstet Gynecol. 2007;46(2):171-3.

37. Shojai R, Chaumoitre K, Chau C, Panuel M, Boubli L, d'Ercole C. Advanced combined abdominal and intrauterine pregnancy: a case report. Fetal Diagn Ther. 2007;22(2):128-30.
38. Iwama H, Tsutsumi S, Igarashi H, Takahashi K, Nakahara K, Kurachi H. A case of retroperitoneal ectopic pregnancy following IVF-ET in a patient with previous bilateral salpingectomy. Am J Perinatol. 2008;25(1):33-6.

39. Hyvarinen M, Raudaskoski T, Tekay A, Herva R. [Abdominal pregnancy]. Duodecim. 2009;125(22):2448-51.

40. Zacche MM, Zacche G, Gaetti L, Vignali M, Busacca M. Combined intrauterine and abdominal pregnancy following ICSI with delivery of two healthy viable fetuses: a case report. Eur J Obstet Gynecol Reprod Biol. 2011;154(2):232-3.

41. Angelova MA, Kovachev EG, Kozovski I, Kornovski YD, Kisyov SV, Ivanova VR. A case of secondary abdominal pregnancy after in vitro fertilization preembryo transfer (IVF-ET). Open Access Maced J Med Sci. 2015;3(3):426-8.

42. Brouard KJ, Howard BR, Dyer RA. Hepatic pregnancy suspected at term and successful delivery of a live neonate with placental attachment to the right lobe of the liver. Obstet Gynecol. 2015;126(1):207-10.

43. Hymel JA, Hughes DS, Gehlot A, Ramseyer AM, Magann EF. Late abdominal pregnancies ( $>/=20$ weeks gestation): a review from 1965 to 2012. Gynecol Obstet Investig. 2015;80(4):253-8.

44. Rombauts L, McMaster R, Motteram C, Fernando S. Risk of ectopic pregnancy is linked to endometrial thickness in a retrospective cohort study of 8120 assisted reproduction technology cycles. Human Reprod (Oxford, England). 2015;30(12):2846-52.

\section{Submit your next manuscript to BioMed Central and we will help you at every step:}

- We accept pre-submission inquiries

- Our selector tool helps you to find the most relevant journal

- We provide round the clock customer support

- Convenient online submission

- Thorough peer review

- Inclusion in PubMed and all major indexing services

- Maximum visibility for your research

Submit your manuscript at www.biomedcentral.com/submit

) Biomed Central 